\title{
David Oliver: Missed GP appointments are no scandal
}

\author{
David Oliver consultant in geriatrics and acute general medicine
}

Berkshire

Last month, NHS Digital's analysis of data on patients missing GP appointments ${ }^{12}$ was eagerly reported by the mainstream media. "NHS England loses $£ 216 \mathrm{~m}$ a year to missed GP appointments," the Guardian said. ${ }^{3}$

The data were on primary care sessions with GPs, nurses, or therapists in the 12 months to 31 October 2018. Some $90 \%$ of practices were included, and $40 \%$ of appointments reported were booked on a same day basis. ${ }^{4}$ NHS Digital found that around one in 20 of the 307 million available appointments was missed without enough notice to give the slots to other patients. It estimated the average cost of each appointment as $£ 30$.

The BBC reported the story in similar terms to the Guardian, although it included some broader context and explained that the cost calculation required some big assumptions and sleight of hand. ${ }^{5}$ But most media outlets, including the Daily Mail, ${ }^{6}$ were happy simply to repeat NHS England's press release ${ }^{7}$ on the NHS Digital figures uncritically.

So-what was the story behind the story? In isolation, the $£ 30$ figure does little to further our understanding of what we might expect or why.

For starters there's no clear, retrospective, like-for-like evidence that the rate of missed appointments has risen in recent years. ${ }^{8}$ And we have little idea whether one in 20 appointments missed is better or worse than what we'd see in other primary care systems worldwide. Maybe only one in 20 missed is a good result. And, by comparison, the "did not attend" rates in hospitals are more like one in $10 .^{9}$

Then there are the potential reasons for non-attendance. Patients may have life limiting, long term conditions. They may have chronic mental health problems or chaotic lifestyles. They may have responsibilities as carers or may themselves depend on carers, who may be unwell. Their access to transport may be limited. They may have become acutely ill or may have tried to contact the practice and not managed to do so in time to free up an appointment.

People favoured draconian solutions for non-attenders, such as fines, suspension, or removal of access to general practices
Furthermore, do we really believe those calculations of expense and opportunity cost? General practice is not funded on a fee-for-appointment basis. Salary costs and overheads don't change because some appointments are cancelled. Clinics are booked with the expectation that some appointments will be cancelled, and the gaps allow extra time for other patients. Seeing other patients in those slots would impose additional costs.

I'm disappointed that NHS England put out these lines-and the largely uncritical, analysis-free reporting strikes me as odd. Even more depressing was the public's reaction in so many rapid responses to articles, letters to newspapers, on social media, and in radio phone-ins. People often favoured draconian solutions for non-attenders, such as fines, suspension, or removal of access to general practices.

Where's the compassion or the desire to understand? Maybe more balanced and nuanced reporting would help. But initial press releases focused on individual responsibility and, by inference, individual blame.

Competing interests: See www.bmj.com/about-bmj/freelance-contributors/davidoliver.

Provenance and peer review: Commissioned; not externally peer reviewed.

1 lacobucci G. Sixty seconds on ... missed GP appointments. BMJ 2019;364:169. 10.1136/bmj.l69 30609997

2 NHS Digital. GP appointments data published. 6 Dec 2018. https://digital.nhs.uk/newsand-events/latest-news/gp-appointments-data-published.

3 Siddique H. NHS England loses $£ 216 \mathrm{~m}$ a year to missed GP appointments. Guardian 2 Jan 2019. https://www.theguardian.com/society/2019/jan/02/nhs-england-loses-216mper-year-missed-gp-appointments.

4 NHS Digital. Appointments in general practice, October 2018 [PAS]. 6 Dec 2018. https:/ /digital.nhs.uk/data-and-information/publications/statistical/appointments-in-generalpractice/oct-2018.

5 Missed GP appointments "cost NHS England £216m." BBC News 2 Jan 2019. https:// www.bbc.co.uk/news/health-46732626.

6 Pickles K. Missed doctors' appointments cost the NHS £216 million a year, with one in every 20 patients failing to turn up. Daily Mail 2 Jan 2019. https://www.dailymail.co.uk/ news/article-6545963/Missed-doctors-appointments-cost-NHS-216million-year-one-20patients-failing-turn-up.html.

7 NHS England. Missed GP appointments costing NHS millions. 2 Jan 2019. https://www. england.nhs.uk/2019/01/missed-gp-appointments-costing-nhs-millions/.

8 Full Fact. The total number of missed GP appointments. 27 Jan 2017. https://fullfact.org/ health/total-number-missed-gp-appointments/.

9 Royal College of Physicians. Outpatients: the future-adding value through sustainability. 9 Nov 2018. https://www.rcplondon.ac.uk/projects/outputs/outpatients-future-adding-valuethrough-sustainability. 
Published by the BMJ Publishing Group Limited. For permission to use (where not already granted under a licence) please go to http://group.bmj.com/group/rights-licensing/

permissions 